quartz, which was broken off the large piece, revealed two patches of gold, both of which together, if removed from the matrix, would probably produce about a dwt. (pennyweight) of the metal; whilst several small masses or nuggets were found adhering to the small broken fragments of quartz at the bottom of the pail in which the rock was washed, the largest of which contained about ten or twelve grains of gold. From some specimens in which no gold was perceptible to the naked eye, and had been selected for analysis, a small nugget weighing three grains was obtained in the dust of the bag in which the specimens were carried. In the specimen from Fox Hill the metal occurs thickly in the minutest specks, scarcely, if at all, perceptible to the naked eye, but readily recognised under the lens, where it chiefly surrounds a small patch of chlorite.

The rock formation intersected by these auriferous quartz veins is of Huronian or Intermediate age, or the group of strata next below the aspidella slates of St. John's. The group consists chiefly of greenish fine-grained felsite slates, which, judging by the weathering of the exposed surfaces, are also magnesian and ferruginous. The cleavage is exactly coincident with the bedding, and the slates occasionally split into very fine laminæ, but frequently into strong stout slabs, which are used to a considerable extent at Brigus for paving, for hearthstones, and for building foundations and walls.

A rough and hummocky belt of country from three-quarters to one mile wide, which forms the nucletus of the peninsula between Bay-de-Grave and Brigus Harbour, is thickly intersected by reticulating quartz veins varying in thickness from less than an inch to upwards of a foot, which often appear to ramify from a central boss or great mass of quartz, often extending over many square yards, and usually forming low isolated hummocks or hills. The general run of the belt is as nearly as possible north-east and south-west from the true meridian. Although many of the veins, both small and large, may be seen for considerable distances to run exactly parallel with the bedding, the net-work of the whole mass runs obliquely to the strike of the beds, which are also minutely intersected by the smaller veins crossing and reticulating in all directions.

The resemblance in general character of the strata with their included auriferous quartz veins in Newfoundland to those of Nova Scotia is striking, although accnrding to Dr. Dawson the auriferous country of Nova Scotia is probably of Lower Silurian age, while that of Newfoundland is undoubtedly unconformably below the Primordial group, which, with abundant characteristic fossils, skirts the shores of Conception Bay.

That a large area of country in the regions referred to is auriferous there can scarcely be a doubt, although nothing short of actual mining and practical experience can possibly prove what the value of the produce may be, or whether the prospects of obtaining a remunerative return for the necessary outlay are favourable or otherwise. The specimens which have been obtained, although an unquestionable evidence of the presence of the precious metal, cannot by any means be taken as indicative of a certain average yield. An analysis of quartz collected, in which gold is imperceptible to the naked eye, may aid in reveal ing some evidence of its constancy, and may throw some light upon the possible average of superficial contents over certain areas under similar circumstances; but it may safely be predicted that the irregularities of distribution, so conspicuously displayed by the veins on the surface, will extend beneath it, and that it will be mainly on the stronger and more persistent bands, where intercalated with the strata, that mining will extend to any considerable depth.

The indications of gold in Newfoundland are certainly sufficiently favourable to merit a fair trial; and there are good reasons to hope and expect that ample capital applied to skilled and judicious labour may be found remunerative to future adventurers, while a new industry will be added to give employment to the labouring population of the island, and possibly bring this despised and but little-known colony into more prominence and consideration abroad than it hitherto has enjoyed.

\section{A SPEED GOVERNOR FOR CONTINUOUS MOTION}

IN NATURE, vol. xxiii. p. 6r, a speed governor for’a chronograph is described, the invention of the Astronomer-Royal, in which a conical pendulum acts on a paddle moving'in a viscous fluid, so as to make it dip more deeply into the fluid when the speed is increased. A similar apparatus, with a spring instead of a pendulum, has recently been applied by me to a clock driving a recording seismograph whose motion is required to be con tinuous and fairly uniform. As the apparatus is very simple and easily made, requiring no nice fitting, and has proved itself to be a very effective governor, a description of it may perhaps be useful.

$a$ is a vertical spindle driven by the clock, and making about one turn per second. Near the top of it a cross-bar is fixed, whose ends are forked, and in them are jointed two bell-crank levers $b c, b c$. At the top of $b b$ are two masses, which in my instrument are two smooth-bore musket balls. These are tied together by a spiral spring between two hooks at the top. At the ends of $c c$ are two flat paddles, and when the balls fly out from the axis of rotation the paddles dip into glycerine contained in the annular trough $d d$, which is shown in section. The trough rests on the top of the clock frame. By using only one spring, instead of tying each ball to the spindle by a separate spring, I secure that the pull inwards is necessarily the same for both.

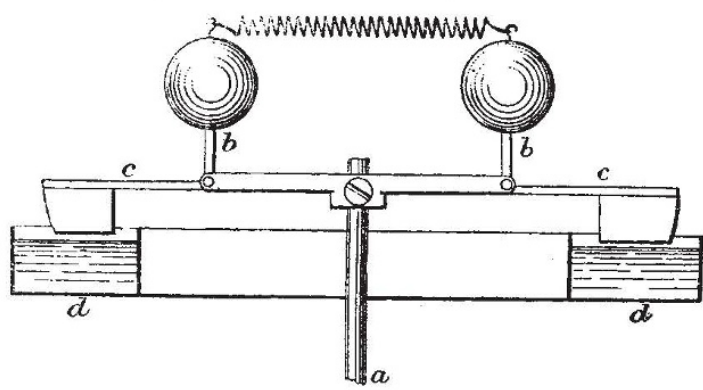

As the balls go out a component of their weight comes into action, helping this motion and opposed to the pull of the spring. For small displacements this force increases very nearly in proportion to the displacement, and hence, by choosing a spring of suitable stiffness, a small change of speed can be made to produce a relatively very large displacement, the proper condition for approximate isochronism.

A governor whose actual size is about twice that of the sketch, roughly made in my laboratory, gives only a slight rise in speed when the driving weight is doubled, and works very smoothly. The apparatus can easily be applied to a clock, perhaps most easily by rolling contact between a horizontal disk on $a$ and a vertical disk on one of the axles of the clock, and it gives sufficient control for many purposes. If great accuracy were required the resultant effect of change of temperature on the elasticity of the spring and on the viscosity of the fluid might be corrected by making $c$ of two metals, so as to bend and raise or lower the paddles. It is well to put stops to prevent the balls from falling inwards beyond the vertical position.

The University, Tokio, Japan, January 21

\section{UNIVERSTTY AND EDUCATIONAL} INTELLIGENCE

OXFORD. - The electors to the Radcliffe Travelling Fellowship have, after examination, awarded the Fellowship to Mr. A. J. Anderson, B.A., late Natural Science Demy of Magdalen College.

The examiners for the Burdett-Coutts (Geological) Scholarship have recommended Mr. J. B. Nias, B.A., scholar of Exeter College, for the scholarship.

The Junior Studentships in Natural Science at Christchurch have been awarded to Mr. G. C. Chambres, Commoner of Balliol College, and late of Dulwich School, and to Mr. R. E. Moyle (private tuition). Proxime accessit, Mr. C. D. Spencer, of Clifton College, Mr. W. C. Hudson was elected to an Exhibition in Natural Science.

The various lecturers and demonstrators in physics met last week at the instance of Prof. Clifton, and arranged a scheme of lectures for next term, similar to that carried out during the present term. The object of the scheme is to divide the subjects among the independent college and university lecturers, so that students may attend, by going from one lecturer to another, all the lectures required for any particular course of study.

THE annual meeting of the Governors of the City and Guilds of London Institute for the Advancement of Technical Educa- 